\title{
MODA: ASPECTOS DISCURSIVOS DA APARÊNCIA
}

\author{
Carol Barreto ${ }^{1}$ \\ Leandro Soares da Silva²
}

RESUMO: Este artigo visa elaborar uma análise introdutória dos discursos expressos por meio da aparência e da moda, considerando a sua presença como um suplemento ao corpo, e à materialidade do gênero em suas várias posicionalidades, através dos marcadores sociais das diferenças - raça/etnia, gênero, sexualidade, orientação afetivo-sexual, geração, classe social dentre outras categorias - com as quais moda, aparência e corporalidade se articulam. Propóe-se que se pense moda a partir dos seus processos criativos, com ênfase no estudo da diferença, a fim de promover uma abrangência maior de sua atuação, a despeito dos estudos gêneros tradicionais que encaram o assunto sob a perspectiva feminina e hegemônica.

PALAVRAS-CHAVE: Moda; Aparência; Raça/Etnia; Gênero/ Sexualidade.

ABSTRACT: This article aims to develop an introductory analysis of the speeches expressed through the appearance and fashion, considering its presence as a supplement to the body, and the materiality of the gender in its positionalities through the social markers of differences - race / ethnicity, gender, sexuality, emotional and sexual orientation, generation, social 
class among other categories - with which fashion, appearance and corporeality are articulated. It is proposed to think fashion from their creative processes, with emphasis on the study of the difference in order to promote greater coverage of its activities, despite the traditional gender studies that take these issues in a female and hegemonic perspective.

KEYWORDS: Fashion; Appearance; Race / Ethnicity; Gender / Sexuality. 
Uma das principais formas sociais de afirmação identitária é a aparência e por meio do vestuário e da moda reproduzimos formas estereotipadas de representação das identidades ou subvertemos essas mesmas normas arbitrárias. Compreendendo a Moda como Linguagem, estudar seus aspectos simbólicos, estéticos e ideológicos na expressão e normatização das identidades, por meio da caracterização dos códigos de gênero, sexualidade, raça/etnia, geração ou classe social, se impõe necessário por observar que ainda hoje os grupos majoritários em representatividade sintonizam, por meio da eleição dos padrões de beleza e de bondade, aquilo que deve ser reproduzido pela massa de consumidoras de seus produtos e discursos.

Não obstante, observo que não é sempre do efêmero e coletivo que a moda se faz, antes disso é base para manifestação individual - que sempre será coletiva em certa medida - de agenciamento político. Assim, neste artigo buscaremos discorrer sobre a maneira como a moda se coloca como aspecto central na expressão das identidades, elaborando uma análise das construções discursivas e imagéticas expressas tanto nos processos criativos envolvidos no design de moda, através da reflexão teórico-prática acerca das relações entre moda, aparência e ativismo político, pretendendo averiguar de que maneira nosso pertencimento étnico-racial, caracteres de gênero e sexualidades, são anunciados na aparência e questionar se não seria esta mesma um elemento marcador: tais características podem ser dissociadas da aparência? Assim, buscando compreender como a construção da aparência elabora-se em intersecção com os marcadores sociais da diferença, questionamos: de que modo a aparência emana agenciamento político? Que corporalidades, intervenções estéticas e gestual, nesse conjunto de elaboração da aparência, podem ser compreendidas como ativismo político nos corpos e no design de moda? 
Para uma mulher feminista negra, o seu cabelo será parte importante de expressão anti-racista como descreve bell hooks ${ }^{3}$ em seu texto "Alisando nosso cabelo" (HOOKS, 2005, p.03). Para uma transfeminista a expressão de uma "corporalidade não padrão" poderá representar uma maneira de desconstruir os ditames que definem os padrões de excelência de gênero - binários, cisexistas, heteronormativos, classistas e racistas - e desenharse centralizando na visualidade seus discursos políticos. Diante disso, sob o ponto de vista das interseccionalidades, podemos interpretar as técnicas e discursos que compõem a elaboração da aparência, compreendendo a construção da exterioridade como processo criativo individual, análogo aos processos criativos em design de moda.

\section{MODA COMO PRODUÇÃO DA CULTURA \\ E DA SOCIABILIDADE CONTEMPORÂNEA}

A arte, o design e a moda há muito tempo deixaram de ser vistas como universos herméticos ou simples entretenimento, para serem reconhecidas como espaço de emancipação ou de exercício do controle da história de vida de milhões de pessoas. Por meio de seus produtos e dos grupos sociais que nesse âmbito tem garantidas suas falas e representações, podemos corroborar à manutenção das assimetrias sociais ou a desconstrução delas. Nessa conjuntura, as categorias de análise que sustentarão a investigação proposta são o conceito de Cultura; que segundo Clifford Geertz trata-se de um fenômeno que se compõe a partir das teias de significados tecidas pelas pessoas e através das quais se enxerga o seu mundo, compondo um sistema simbólico que formaria a estrutura imaginativa de uma sociedade: 
Como sistemas entrelaçados de signos interpretáveis (o que eu chamaria símbolos, ignorando as utilizações provinciais), a cultura não é um poder, algo ao qual podem ser atribuídos casualmente os acontecimentos sociais, os comportamentos, as instituições ou os processos; ela é um contexto, algo dentro do qual podem ser descritos de forma inteligível - isto é, descritos com densidade. (GEERTZ, 1989, p. 10).

Coadunando com a ideia de Cultura como contexto, produção de sentido e de significado, uma vez materializada no corpo elabora-se o fenômeno da moda como modus de inscrição cultural e meio de expressão social que possibilita a constituição de diferentes formas de gerenciamento do parecer, composto pelo repertório de imagens a serem interpretadas e materializadas pelas pessoas a partir do acervo de peças de roupa, acessórios, cosméticos, dentre outros aspectos referentes à alteração ou composição desta aparência, como o gestual e o comportamento ${ }^{4}$. Dentre as articulações entre o conceito de moda e cultura, os escritos de Malcolm Barnard nos auxiliam a pensar na importância da moda e da indumentária como "algumas das maneiras pelas quais a ordem social é experimentada, explorada, comunicada e reproduzida. Através da moda e da indumentária nos constituímos como seres sociais e culturais" (BARNARD, 2003, p.64).

Coadunando com a idéia de produção de sentido e significado materializadas inclusive no corpo, o filósofo italiano Giogio Agamben reconhece a moda como o melhor exemplo de sua definição do que é contemporâneo. Segundo ele,

Aquilo que define a moda é que ela introduz no tempo uma peculiar descontinuidade, que o divide segundo 
a sua atualidade ou inatualidade, o seu estar ou o seu não-estar-mais-na-moda (na moda e não simplesmente da moda, que se refere somente às coisas). Essa cesura, ainda que sutil, é perspícua no sentido em que aqueles que devem percebê-la a percebem impreterivelmente, e, exatamente desse modo, atestam o seu estar na moda; mas, se procuramos objetivá-la e fixá-la no tempo cronológico, ela se revela inapreensível. Antes de tudo, o "agora" da moda, o instante em que esta vem a ser, não é identificável através de nenhum cronômetro. Esse "agora" é talvez o momento em que o estilista concebe o traço, a nuance em que confia ao desenhista e em seguida à alfaiataria que confecciona o protótipo? Ou, ainda, o momento do desfile, em que a veste é usada pelas únicas pessoas que estão sempre e apenas na moda, as mannequins, que, no entanto, exatamente por isso, nela jamais estão verdadeiramente? Já que, em última instância, o estar na moda da "maneira" ou do "jeito" dependerá do fato de que pessoas de carne e osso, diferentes das mannequins - essas vítimas sacrificiais de um deus sem rosto - o reconheçam como tal e dela façam a própria veste. (AGAMBEN, 2009, p. 66-7)

Agamben nos permite chamar atenção para moda como um ato performativo, para a característica da performance como aquele processo de vir-a-ser que só se cumpre no momento exato em que é produzido, isto é, citado. Sua importância está na medida em que se deixa perceber as ondas de transformações em curso operadas nesse sistema.

Como um ato performativo e não apenas como elemento físico e material, o conceito de moda sempre estará aludindo à noção de aparência como meio de registro da nossa subjetividade em negociação com os padrões socioculturais vigentes e assim buscamos desconstruir 
a ideia de superficialidade que se atrela comumente ao termo, acionando a escrita de Renata Pitombo Cidreira:

Caluniam-se as aparências. Tomam-lhe invariavelmente por enganadoras. Sob o pretexto de que elas não dizem sempre a verdade - o que é verdadeiro, lhe acusam de mentir sem cessar, mas as aparências revelam mais frequentemente do que enganam. Elas não têm o que esconder, porque estão inteiras no visível. (CIDREIRA, 2005, p. 17).

A autora tem trabalhado para elaborar uma perspectiva compreensiva da moda na contemporaneidade, a fim de decodificar como a moda opera nos processos de conhecimento e encenação de nós mesmas, a partir de uma perspectiva sócio-antropológica da comunicação:

É possível pensar a subjetividade enquanto atividade plástica, formal e plasmadora, que em última instância se mostra enquanto estilo. Os traços identitários seriam configurados numa forma que se exibe no próprio corpo, no campo da dinâmica vestimentar. Assim, comparecem de modo intenso, a força da aparência e da composição do look na contemporaneidade, marcada pela visualidade. (CIDREIRA, 2014, p. 92-93)

Partindo dessa argumentação sobre as relações entre moda, subjetividade, identidade e estilo, os marcadores sociais das diferenças são discursos materializados na linguagem da aparência e na corporalidade das pessoas e, assim, aspectos como gênero, sexualidade, raça/etnia, classe social, acessibilidade e geração, não somente operam como elementos 
de identificação, mas articulam-se às matrizes produtoras das desigualdades. Assim, numa proposta de análise desses discursos, considerando a moda como um suplemento ao corpo e à materialidade do gênero em suas várias posicionalidades, podemos compreendê-la como espaço de concretização dos marcadores sociais das diferenças.

\section{OS CORPOS E AS NARRATIVAS DA APARÊNCIA}

A aparência é uma modalidade do visível que conta uma história. Chamamos de narrativa da aparência o corpo tornado signo através dos seu métodos de adorno e cuidado, investidos sobre ele pela contingência histórica e pela cultura. $\mathrm{O}$ corpo nu é um significante que remete apenas a si mesmo, às suas funções mais básicas, como o corpo do cadáver na aula de anatomia. Um corpo nu é objeto, colocado numa composição para dela extrair estímulo, como na arte erótica e na pornografia tradicional, ou considerado como exemplo da superação de uma cultura sobre a outra, como o corpo do índio, cuja nudez (mesmo crivada de adornos) é usada para "atestar" - sob a perspectiva do colonizador - seu pertencimento a um estágio "atrasado" de civilização.

Por isso o corpo, no contexto cultural e histórico, nunca está nu, mas sempre remetendo a outras instâncias formadoras da nossa compreensão de humanidade. Tal um signo, esse corpo remete sempre a outros corpos, de maneira que a origem e o significado de sua presença se confundem com as tramas com que a própria noção de pessoa é construída. Merleau-Ponty havia escrito que "se dizemos que a cada momento o corpo exprime a existência, é no sentido em que a fala exprime o pensamento" (MERLEAU-PONTY, 2006, p. 229). Segundo o filósofo, 
A existência corporal que crepita através de mim sem minha cumplicidade é apenas o esboço de uma verdadeira presença no mundo. Pelo menos ela funda sua possibilidade, ela estabelece nosso primeiro pacto com ele. Posso muito bem ausentar-me do mundo humano para reencontrar em meu corpo a mesma potência, dessa vez sem nome, pela qual estou condenado a ser. Pode-se dizer que o corpo é "a forma escondida do ser próprio" ou, reciprocamente, que a existência pessoal é a retomada e a manifestação de um dado ser em situação. (MERLEAU-PONTY, 2006, p. 229)

As narrativas da aparência são a visibilidade de um corpo tornada legível. Os padrões de beleza, nesse caso, são a normatividade imposta ao corpo de uma pessoa, eles representam a uniformidade, através da repetição que busca submeter os corpos a um regime de controle, que tem menos a ver com o que é considerado belo do que com o que é considerado aceitável. Se uma mulher negra se recusa a alisar os cabelos, sua recusa implica numa outra significação, seu corpo é investido de outro sentido, que não só a recusa aos padrões, mas uma afirmação daquilo que foge ao padrão, como o reconhecimento de sua ancestralidade, por exemplo. Por isso a aparência propõe uma narrativa a situar este ou aquele corpo na sua relação com outros corpos, semelhantes ou diferentes, no bojo da cultura e da história.

Também a suplementaridade da moda em relação ao corpo vem da ideia de que este nunca é considerado, enquanto nu, um signo prenhe de sentidos, mas como que tornado legível e vivo através dos instrumentos da moda. É assim que Jacques Derrida se refere ao suplemento:

O suplemento acrescenta-se, é um excesso, uma plenitude enriquecendo uma outra plenitude, a culminação da 
presença. Ele cumula e acumula presença. É assim que a arte, a tekhné, a imagem, a representação, a convenção etc, vem como suplemento da natureza e são ricas de toda esta função de culminação. (DERRIDA, 2000, p. 177)

A lógica do suplemento derridiano é que ele perigosamente pode substituir aquilo que ele visa suprir:

Mas o suplemento supre. Ele não acrescenta senão para substituir. Intervém ou se insinua em-lugar-de; se ele representa e faz imagem, é pela falta anterior de uma presença. Suplente e vicário, o suplemento é um adjunto, uma instância subalterna que substitui. Enquanto substituto, não se acrescenta simplesmente à positividade de uma presença, não produz nenhum relevo, seu lugar é assinalado na estrutura pela marca de um vazio. Em alguma parte, alguma coisa não pode-se preencher de si mesma, não pode efetivar-se a não ser deixando-se colmar por signo e procuração. (DERRIDA, 2000, p. 178)

Há, portanto, uma relação que não é dependente, mas interdependente, se considerarmos que o corpo só pode ser eleito como produto cultural quando consignado pela moda, que, por sua vez, não se cumpre sozinha sem o auxílio do corpo. O que chamamos de aparência, nesse contexto, não é uma região abstrata que envolve os corpos, mas o próprio volume que o corpo como signo produz no espaço. É uma modalidade do vísivel. Didi-Huberman afirma que "ver só se pensa e só se experimenta em última instância numa experiência do tocar". (DIDI-HUBERMAN, 2010, p. 31) Do mesmo modo, Merleau-Ponty havia escrito antes dele:

É preciso que nos habituemos a pensar que todo visível é moldado no sensível, todo ser táctil está votado de alguma 
maneira à visibilidade, havendo, assim, imbricação e cruzamento, não apenas entre o que é tocado e quem toca, mas também entre o tangível e o visível que está nele incrustado, do mesmo modo que, inversamente, este não é uma visibilidade nula, não é sem uma existência visual. Já que o mesmo corpo vê e toca, o visível e o tangível pertencem ao mesmo mundo. Maravilha muito pouco notada é que todo movimento de meus olhos - ainda mais, toda deslocação de meu corpo - tem seu lugar no mesmo universo visível, que por meio deles pormenorizo e exploro, como, inversamente, toda visão tem lugar em alguma parte do espaço táctil. (MERLEAU-PONTY, 2007, p.131)

O volume que o corpo produz, isto é, a aparência, altera o próprio espaço onde o corpo se insere, no sentido em que afirma uma presença sempre diferida de outros signos em jogo. Quando estou de luto, se sigo uma norma cultural para indicar este estado, envio através da minha aparência e do meu gestual uma série de indícios que vão significar o meu corpo para as outras pessoas compreenderem este dado que, apesar de dizer respeito apenas a mim e neste determinado momento, está consignado por signos comuns a todas as pessoas de minha cultura. De modo reverso, se quero declarar aos outros minha insubmissão a uma determinada norma, ou se quero afirmar politicamente um aspecto de minha identidade, subverto ou frusto as expectativas desses signos comuns, ou padrões. $\mathrm{O}$ aspecto mais contundente, contudo, diz respeito à performance de gênero, não porque ela declara sobre alguém sua conformidade ou não aos padrões, mas porque ela define a própria noção de pessoa.

A produção da performance de gênero é submetida às normas da aparência, isto é, o que é e não é aceitável como 
corpo legível. A construção do humano passa, então, a ser uma relação que nunca está afastada dos padrões sobre a corporalidade. É nesse sentido que Judith Butler afirma:

O corpo sugere mortalidade, vulnerabilidade, agência: a pele e a carne nos expõem ao olhar dos outros mas também ao toque e à violência. $O$ corpo pode ser agência e instrumento deles também, ou o lugar onde "fazer" e "ser feito" se torna equívoco. Apesar de lutarmos por direitos sobre nossos corpos, os próprios corpos pelos quais lutamos não são totalmente apenas nossos. O corpo tem uma dimensão pública invariável; constituído como fenômeno social na esfera pública, meu corpo é e não é meu. (BUTLER, 2004, p. 21).

Em outro contexto, Butler escreve que mesmo o corpo "falho", aquele cuja narrativa da aparência visa a subversão ou a inconformidade, tem seu lugar na medida em provê sentido à própria norma:

[...] será tão importante pensar sobre como e para que fim corpos são construídos quanto pensar sobre como e para que fim os corpos não são construídos e, além disso, para perguntar depois como os corpos que não conseguem se materializar fornecem o "exterior" necessário, se não o suporte necessário, para corpos que, ao materializar a norma, se qualificam como corpos que importam. (BUTLER, 2011, p. xxiv)

A importância de se destacar o lugar da moda nesse processo está declarada aí, na sua capacidade de prover ferramentas e mecanismos que vão significar um corpo, construir ou desconstruir sua humanidade, apresentar alternativas aos 
padrões ou até destituí-los, e fornecer às pessoas um meio de expressão de suas identidades.

A questão da legitimidade passa a ser crucial nesse processo, porque ela se relaciona com as configurações que uma cultura possui para definir os corpos. O corpo ilegítimo, o corpo rebelde, o corpo deformado ou envelhecido, o corpo sexuado e o corpo político vão reconfigurar as opções e buscar legitimidade no sistema da moda, tanto por não ser possível mais a nostalgia da originalidade quanto porque é assim que se amplia a noção de pessoa que buscamos, isto é, aquela onde os corpos inconformes têm importância. Nenhuma narrativa da aparência é neutra, muito menos sem substância, mais algumas são mais normativas do que outras e, por isso, sua legibilidade é tão comum que se torna invisível. Invisível no sentido de naturalizado. Se toda norma aspira a ser considerada natural, ou seja, alçada à ideia de que é normal, sua invisibilidade se dá na medida em que ela neutraliza a potência dos corpos. Aqueles corpos que ferem essa suposta naturalidade são, por outro lado, invisibilizados no sentido de que só servem para marcar a diferença ou a anormalidade. Buscar a legitimidade desses corpos é também tornar visíveis os corpos "normais", demonstrar que eles também se constroem a partir da arbitrariedade.

\section{MODA E PROCESSOS CRIATIVOS}

O universo da moda é comumente reconhecido pela sua expressão material mais mutante: o vestuário. No entanto seus aspectos intangíveis, como produção de sentido e significado na materialização das posicionalidades de raça/etnia, gênero 
e sexualidades, pouco foram problematizados por autoras (es) que pesquisam na área de Moda no Brasil e nesse campo ainda se produzem conhecimentos pautados em discursos de heteronormatividade e branquitude.

De outro lado, o campo interdisciplinar dos Estudos Feministas e de Gênero trata na maioria das vezes de corpos não-trajados, sendo que sua aparência e a potência dessa linguagem é pouquíssimo citada, compondo a contradição desejada pelos grupos hegemônicos que desenham a moda como um campo para exercício de seus padrões, sitiado pelas elites. No histórico da construção do campo dos estudos feministas e de gênero, quando a visualidade dos corpos foi analisada, o termo gênero aparece como sinônimo de mulher.

A importância da reflexão sobre a linguagem da moda e da aparência na materialização das relações de poder, rompendo com a perspectiva feminista hegemônica, que, por sua vez, persiste na valorização da temática puramente política e geralmente distanciada da verve cultural e artística, poderia assumir a perspectiva do Feminismo da Diferença ${ }^{5}$ para balizar tal empreendimento numa abordagem interseccional, que na história dos Feminismos "expandiu o conceito de gênero e passou a formulá-lo como parte do conjunto heterogêneo das relações móveis, variáveis e transformadoras do campo social" (COSTA \& AVILA, 2005, p.04).

É possível pensar a Moda através das estratégias de seus processos criativos, a fim de explicitar como seu universo se constrói e reforça o modelo hegemônico androcêntrico, heteronormativo e branco, apontar como ícones dos padrões de sofisticação e beleza comumente impostos, as linguagens do desfile e do editorial de Moda como um 
Processo de criação de imagens e performance artística relacionadas a um conceito canônico que reproduz em moda padrões recorrentes - comumente conhecidos e criticados por produzir modelos de beleza hegemônicos, eurocentradoseestereotipados"(BARRETOeROSA,2012). ${ }^{6}$

A partir daí, trata-se não somente de verificar como os processos criativos podem subvertê-las, mas também como eles propõem a multi-representação de rostos e corpos brancos, negros, indígenas, afro-indígenas, heteros, homos e transgêneros, considerandoaimportância de fruirecelebrar diversasidentidades.

É fácil observar que por meio da aparência algumas pessoas rompem com os padrões dos grupos hegemônicos e compõem a aparência como ativismo político. Tanto as mulheres negras como as mulheres trans ${ }^{\star}$, por exemplo, são vistas como corpos públicos e acessíveis a tudo e a todos, os cabelos das mulheres negras assim como o genital das mulheres trans ${ }^{\star}$ são alvos de curiosidade e questionamento frequente. Refletir sobre os processos criativos passa por analisar quais técnicas da aparência são úteis como discurso, expressão ideológica e ativismo, expandindo suas fronteiras para visibilizar a existência dos "gêneros inconformes". Segundo Viviane Vergueiro, o termo marca "o caráter inferiorizado das inconformidades de gênero em relação à norma cisgênera, evidenciando os elos comuns de colonização que permeiam estas individualidades." (VERGUEIRO, 2012, p. 7).

Como elemento constitutivo das formas de produção e reprodução de conhecimento, a roupa e o corpo são elementos indissociáveis na cultura contemporânea e dessa maneira, em busca do estudo dessa linguagem, compreendemos a relevância de se abrir um debate para a multiplicidade de referências artísticas e políticas no campo da moda e das artes, dentro da perspectiva do que chamamos de possíveis iconografias pós-coloniais. Como linguagem e expressão de discurso e 
ideologia, devemos pensar moda e aparência como ativismo político num processo de descolonização, como nos provoca Cláudia Pons em sua tese sobre o Pensamento Feminista Negro:

A descolonização de saberes e (também) de experiências fundamenta, portanto, uma pesquisa emancipatória, representando "de um lado, um projeto social e político de transformação das relações sociais e, de outro, postula um projeto científico alternativo de elaboração de conhecimento" (PONS, 2012, p. 67).

As produções de moda assinada por pessoas e grupos minoritários em representatividade podem e devem trilhar por caminhos emancipatórios.

Por fim, refletir sobre a elaboração das narrativas da aparência também se trata de legitimar a existência dos corpos. Pensar em corpo como algo além da prescrição da natureza pode ser muito potente no sentido de articular um campo teórico multidisciplinar, uma vez que há uma diversidade de corpos e concepções estéticas, cuja diversidade muitas vezes não é visibilizada em pesquisas sobre o assunto. Será preciso notar nossas aparências como um espelhamento das construções culturais, sociais e midiáticas, pensando cada corpo trajado como feição do seu grupo de pertença, cujas representações mais ou menos recorrentes lhes conferirão imagens de autoridade ou de subalternidade. Como elemento constitutivo das formas de produção e reprodução de conhecimento, a moda e o corpo são elementos indissociáveis na sociabilidade ocidental urbana contemporânea e, dessa maneira, no estudo dessa linguagem, compreendemos a relevância de se abrir um debate para a multiplicidade de referências artísticas e políticas nesse campo. 


\section{NOTAS}

${ }^{1}$ Caroline Barreto de Lima é designer de moda, professora do Bacharelado em Estudos de Gênero e Diversidade, Departamento de Ciência Política, FFCH - UFBA. Doutoranda no Programa de Pós-Graduação em Cultura e Sociedade - PosCultura - IHAC - UFBA. Pesquisadora do Núcleo de Estudos Interdisciplinares sobre a Mulher - NEIM, na área de Gênero, Cultura e Linguagem. E-mail: demodee@gmail.com

${ }^{2}$ Leandro Soares da Silva é professor de Literatura na UNEB, Campus XVIII. Doutorando em Teoria Literária e Literatura Comparada pela UFMG. E-mail: leocapim@gmail.com

${ }^{3}$ A própria autora, feminista negra estadunidense, reivindica a escrita do seu nome em letras minúsculas.

${ }^{4}$ Cf. Barreto, 2008.

${ }^{5} \mathrm{O}$ termo "feminismo da diferença" faz alusão à trajetória norte-americana desse conceito, onde os escritos de Gloria Anzaldúa inauguram o diálogo sobre o discurso da diferença. Cf. ANZALDUA \& MORAGA, 1981.

${ }^{6}$ Texto ainda inédito. 


\section{REFERÊNCIAS}

AGAMBEN, G. O que écontemporâneo? e outros ensaios. Tradução Vinicius Nicastro Honesko. Chapecó, SC: Argos, 2009.

BARNARD, M. Moda e Comunicação. Tradução Lúcia Olinto. Rio de Janeiro: Rocco, 2003.

BARRETO, C.; ROSA, L. Raça, gênero, sexualidade e moda no corpo: performances, escutas e linguagens. No prelo.

BARRETO, C. Moda e expressão sexual: redesenho e construção da aparência no grupo das Travestis de Salvador. Dissertação de Mestrado em Desenho, Cultura e Interatividade. Feira de Santana: Universidade Estadual de Feira de Santana, 2008.

BRAH, A. Diferença, diversidade, Diferenciação. Cadernos Pagu (26), São Paulo, janeiro-junho de 2006: p.329-376.

BUTLER, J. Undoing gender. Nova Iorque: Routledge, 2004.

BUTLER, J. Bodies that matter. Nova Iorque: Routledge, 2011.

BUTLER, Judith. Problemas de gênero: feminismo e subversão da identidade. Rio de Janeiro: Civilização Brasileira, 2010.

CIDREIRA, R. P. A moda numa perspectiva compreensiva. Cruz das Almas - BA: Editora UFRB, 2014.

CIDREIRA, R. P. Os sentidos da moda (vestuário, comunicação e cultura). São Paulo: Annablume, 2005. 
COSTA, C. L. ; ÁVILA, E. Gloria Anzaldúa, a consciência mestiça e o "feminismo da diferença". In: Rev. Estud. Fem., dez 2005, vol. 13, n. 3, p. 691-703.

DERRIDA, J. Gramatologia. Tradução Miriam Chnaiderman e Renato Janine Ribeiro. São Paulo: Perspectiva, 2000, $2^{\mathrm{a}}$ ed.

DIDI-HUBERMAN, G. O que vemos, o que nos olha. São Paulo: Editora 34, 2010.

GEERTZ, C. A interpretação das culturas. Rio de janeiro-RJ: Editora LTC, 1989.

HOOKS, b. Alisando nossos cabelos. Revista Gazeta de CubaUnión de escritores y Artista de Cuba, janeiro-fevereiro de 2005. Tradução do espanhol: Lia Maria dos Santos. Retirado do blog coletivomarias.blogspot.com/.../alisando-o-nosso- cabelo.html

MERLEAU-PONTY, M. Fenomenologia da percepção. São Paulo: Martins Fontes, 2006.

MERLEAU-PONTY, M. O visível e o invisível. São Paulo: Perspectiva, 2007.

VERGUEIRO, V. Pela descolonização das identidades trans*. Anais do VI Congresso Internacional de Estudos sobre a Diversidade Sexual e de Gênero da ABEH. Salvador: Volume 1, Número 1, 2012. Disponível em: http://bit.ly/1a9bt4h. Acessado em: 03.10.2014 